\title{
Ready or Not?
}

\section{An Assessment of Shelf-Ready Materials Management Practices in US Academic Libraries}

\author{
Natalia Tomlin and Irina Kandarasheva
}

Natalia Tomlin (Natalia.Tomlin@liu.edu) is Technical Services Librarian in the Technical Services Department at Long Island University (LIU Post), Brookville, New York, and Irina Kandarasheva (ink2@ columbia.edu) is LC Copy Cataloging Unit Librarian in the Monograph Processing Services Division at Columbia University, New York, New York.

Submitted July 25, 2013; returned to authors with request to revise on October 9, 2013; revision submitted December 14, 2013; tentatively accepted for publication pending minor revision on February 19, 2013; revision submitted March 20, 2014; accepted for publication April 11, 2014.

The authors wish to thank Nisa Bakkalbasi, Assessment Coordinator at Columbia University Libraries (nisa.bakkalbasi@ columbia.edu), for technical assistance with the survey software. We also thank LRTS reviewers and editors for their insightful comments and advice.
This paper analyzes results of a survey on shelf-ready materials management and cataloging practices in US academic libraries with various collection sizes. The survey respondents consisted of managers and librarians in technical services operations. Survey questions addressed topics such as the volume of shelf-ready materials, perspectives on shelf-ready expansion, the effect of local cataloging practices on shelf-ready services, the amount of cataloging and processing errors, and quality control. The majority of participants were from small- and medium-size academic libraries, and print materials were the prevalent format for shelf-ready treatment. Two main reasons for shelf-ready implementation across libraries of all sizes were the need to improve materials turnaround time and the desire to redeploy staff for other projects or tasks.

$\mathrm{T}$ he acquisition of library materials in shelf-ready form is one of the outsourcing strategies implemented by technical services departments to improve efficiency, reduce costs, and increase patron satisfaction. Shelf-ready materials supplied by vendors include physical items accompanied by full bibliographic records and physical processing such as application of barcodes, spine labels, security strips, etc. As the current library environment is moving toward management of electronic resources, the possibility of streamlining receiving, cataloging, and processing of materials in non-electronic format is potentially a very welcome alternative to the traditional acquisitions to cataloging model. While some libraries gained substantial experience in managing shelf-ready operations during the last decade, others are still contemplating the idea or are unsure of the implications that shelf-ready services could have for their libraries' databases and staffing. Potential concerns linked to the implementation of shelf-ready services can include extra review of vendor-supplied records, presence of less than full bibliographic records, and changes in work assignments for technical services staff. The review of current library literature reveals a need for assessment of academic libraries' practices in shelf-ready materials management.

The authors designed a survey to gain insights into different aspects of acquiring shelf-ready materials in US academic libraries with varying collection sizes. The authors were particularly interested in gathering feedback on the quality of bibliographic records for shelf-ready materials and their effect on local cataloging practices, including authority work. The implication of the new cataloging code, 
Resource Description and Access (RDA), and its effect on shelf-ready workflows was also assessed.

\section{Literature Review}

Academic libraries in the United States have been using shelf-ready services as a form of outsourcing for the past fifteen years. The topic itself, however, has not been frequently discussed in library and information science literature. Perhaps the lack of research could be explained by libraries' desire to have sufficient practical experience with shelfready operations before assessing this type of outsourcing. There is almost a ten-year gap between the first case study by Joy and Lugg, which addressed various aspects of shelfready materials management, and the beginning of subsequent publications on this topic in library science journals. ${ }^{1}$ To date, the published research on the use of shelf-ready services in academic libraries is represented mostly by case studies on cost-benefits analysis, bibliographic record quality, and workflow evaluation. In addition, some research data on shelf-ready operations is available in the archives of the cataloging and authorities discussion list Autocat. The following literature review examines these studies and other papers on outsourcing relevant to shelf-ready materials.

A comprehensive review of the literature on outsourcing by Sweetland offers a concise definition of shelf-ready services: "The books (or other material) are catalogued, provided with barcodes, spine labels, covers, and the like by the vendor." ${ }^{\text {F }}$ Furthermore, Shippy and Krug underscore the highly customizable nature of shelf-ready services and define it as a "set of custom services that you design à la carte."33 Joy and Lugg briefly examine the reasons why libraries turned to the shelf-ready option. ${ }^{4}$ Reductions in technical services budgets and the subsequent staffing losses, plus high shipping costs for materials (particularly to libraries in US academic institutions overseas in Hong Kong, Singapore, and Australia) were the main reasons for initial implementation and further expansion of shelf-ready services. Joy and Lugg point out that from a financial point of view, vendors did not significantly benefit by supplying shelf-ready materials. ${ }^{5}$ In fact, the provision of shelf-ready services acted as an added value in the competitive book market. Although libraries began to implement shelf-ready services mainly for budgetary reasons, it is interesting to note that the most recent case studies primarily cited the efficient use of human resources and the desire to improve user services as main reasons for the implementation of shelf-ready services. ${ }^{6}$ Moreover, Shippy and Krug observe that "shelf-ready acquisitions should not be regarded as a means of outsourcing or otherwise reducing staff. Rather, it is a means of freeing your most valuable asset—your staff—so they might better serve your library's users."
Sweetland analyzed data on the number of libraries that used outsourcing for cataloging or physical processing more than a decade ago. ${ }^{8}$ However, his study published in 2001 cannot be used to estimate the expansion of shelfready services at the time because the definition of shelfready encompasses both cataloging and physical processing. Lam's survey of academic libraries reveals that the majority of outsourcing institutions were small- and medium-size libraries. Among that group, shelf-ready services were the most popular form of outsourcing. ${ }^{9}$ Regarding the format of shelf-ready materials, all reports to date address the processing of domestic print monographs, although one study indicates the desire to expand shelf-ready operations to music materials and foreign language monographs. ${ }^{10}$ In addition, a column in Serials Review by Andrade et al. describes the positive experiences of San Diego State University and the University of Calgary libraries in receiving shelf-ready print serials. ${ }^{11}$ Furthermore, Baron briefly discusses the possibility of acquiring shelf-ready audiovisual and out-of-print monographs. ${ }^{12}$ He concludes that the quality of bibliographic records and processing time, combined with high costs, were the impetus for moving to a shelf-ready acquisitions model for these types of library resources. Lastly, Jacoby expresses doubts regarding the future of shelf-ready services expansion in academic libraries because they eliminate or greatly reduce participation by librarians and faculty in the collection development process. ${ }^{13}$ However, one may argue that collection development librarians will still participate in the selection process by either defining the approval profile with the vendor or by placing preselected firm orders for shelf-ready materials. In addition, libraries usually use shelfready services only for part of their acquisitions.

The implementation of shelf-ready services requires collaboration and communication between vendors and libraries to define processing specifications. It also involves significant changes in the workflows for collection development, acquisitions, cataloging, end processing, and library systems staff. For example, acquisitions staff may spend less time processing traditional firm orders, copy catalogers and end processing staff may become available for reassignment to other functions, and collection development staff may become involved with loading bibliographic record sets and promoting the new shelf-ready books. Systems personnel may become engaged in the creation of new software to support the integration of local data into shelf-ready bibliographic records, approval profiling, invoicing, or writing scripts for batch processing of vendor records. Professional catalogers need to collaborate with vendors to provide quality assurance by identifying errors and reviewing records regularly. ${ }^{14}$ Libraries must also carefully examine vendor capabilities and limits of customization regarding local cataloging practices. Bierman and Carter suggested that to implement shelf-ready services, library approval plans must 
have a very low return rate because shelf-ready materials may not be returned or exchanged. ${ }^{15}$

The benefits of shelf-ready services include improved materials turnaround time and financial savings. Various studies mention three to seven days as a range of time required to deliver materials to the shelf using this model. ${ }^{16}$ Schroeder and Howland conducted a cost-benefit analysis of in-house and shelf-ready materials processing at the University of Birmingham library. ${ }^{17}$ The study reveals that the shelf-ready books took 47 percent less processing time and were placed on the shelf thirty-three days sooner as compared to the materials processed in-house. In turn, Bierman and Carter calculated per-title cost for shelf-ready materials by combining vendor and OCLC charges with staff salaries and physical processing fees as $\$ 6.85$ per title. In contrast, the cost of per-title processing using a traditional model was $\$ 8.70$ in staff compensation including fringe benefits, OCLC and suppliers costs, direct cataloging costs and equipment. Consequently, the authors report that shelf-ready materials had a cost of $\$ 2$ less per title. ${ }^{18}$

The move to a shelf-ready model may affect libraries' infrastructure, resulting in the merging of different administrative units such as cataloging and acquisitions departments and additional duties for circulation services. For example, Bierman and Carter describe transferring the processing of shelf-ready titles from acquisitions to circulation staff to speed delivery of books to users. Later during the implementation process, the handling of shelf-ready materials was transferred to cataloging staff because about 25 percent of the bibliographic loads lacked Library of Congress (LC) fulllevel bibliographic records. ${ }^{19}$ Likewise, Walker and Kulczak report on acquisitions staff performing some copy cataloging duties while professional catalogers had to create technical specifications for shelf-ready materials. Because of these changes, two administrative units were consolidated into a single cataloging and acquisitions department. ${ }^{20}$ Potential additional challenges of shelf-ready implementation may include changes to how cataloging statistics are recorded, possible duplicate items, and absence of OCLC control numbers (depending on the source of bibliographic records) for shelf-ready materials in the library database. ${ }^{21}$

\section{Shelf-Ready Materials: Quality of Bibliographic Records}

Sweetland reports the rate of errors in bibliographic records for shelf-ready materials observed in earlier studies. ${ }^{22}$ The data indicated that the error rate falls into a wide range between 0.5 and 30 percent. However, more recent studies document that records requiring in-house action at about 2 percent. According to Walker and Kulczak as well as Lam, such in-house actions may include correcting series headings, call number errors, erroneous location codes, and typographical errors. ${ }^{23}$ Likewise, Barron specifies that manual intervention was needed to modify Dewey call numbers for law materials. ${ }^{24}$

The results of a survey of academic libraries conducted by Lam demonstrate that 81.1 percent of respondents exercised quality control of outsourced materials with the majority of institutions (48.94 percent) checking access points only. The remaining 20 percent of libraries checked all fields in the bibliographic records, 30 percent of respondents checked various combinations of access and non-access points such as call numbers, subject headings, typographical errors and non-English scripts. Moreover, 67 percent of the respondents stated that the quality of cataloging remained the same, and about 25 percent indicated that it increased because of outsourcing. ${ }^{25}$

Walker and Kulczak were the first to specifically address the quality of shelf-ready materials cataloging. ${ }^{26}$ They conducted a year-long review of cataloging records for materials received at the University of Arkansas Library. From their analysis of three samples of books totaling 400 titles, they observed that errors appeared in batches. Among the observed errors, 2 percent were related to mismatched titles or missing records, about 18 percent were national cataloging practices errors such as transcription, MARC coding, errors in name and subject headings and typographical mistakes, yet another 20 percent were local practices errors such as shelf listing and physical processing mistakes. Walter and Kulczak's study provides a comprehensive list of evaluation criteria. In addition to the records that contained errors in national and local cataloging practices, 32 percent of the records included series headings errors such as the wrong form of a series heading or series numbering. Series headings errors at a local level resulted from different tracing and classification practices. The authors conclude that a thorough review of shelf-ready materials is necessary to avoid compromising the integrity of the library's online catalog.

In contrast to Walker and Kulczak's findings, Lam's inhouse survey of copy cataloging error rates before and after outsourcing establishes that the error rate for shelf-ready bibliographic records was very low and was comparable with materials copy cataloged in-house. ${ }^{27}$ Likewise, Schroeder and Howland indicate that, although records cataloged locally were more in line with institutional standards, shelfready records were sufficient for their library's needs. ${ }^{28}$ In an effort to streamline quality control for shelf-ready materials, the University of Florida library created an automation tool named CatQC. ${ }^{29}$ According to Jay, Simpson, and Smith, CatQC is freely available to other institutions by directly contacting the authors. CatQC was designed to eliminate manual review of shelf-ready materials by conducting a cataloging quality report on nine parameters. These specifications were designed to identify minimal-level cataloging 
records, foreign library records, serials, analytics, nonprint formats, untraced series, records requiring alternate titles, the presence of the URL linking to the electronic version of the item, and non-English subject headings.

Regarding physical processing errors, Ballestro reports errors in barcode placement and property stamps, poor placement of call number labels on the spine, and a mismatch of the call number in record and on label based on a sample of 2,734 titles. ${ }^{30} \mathrm{He}$ attributes these issues to quality control problems on the vendor's side. Sanchez surveyed academic, public, special and state libraries with regard to physical processing of shelf-ready materials. ${ }^{31}$ She found that spine labels were the most popular form of physical processing and that binding was the least in demand because of limited library budgets. Forty seven percent of the libraries that she surveyed employed quality control for shelf-ready materials. Among these, 64.7 percent checked for physical processing errors, 35.3 percent compared the book against the bibliographic record to correct description or access issues, and 52.9 percent compared books received against order information to assure that the correct titles were received. Incorrect or wrongly formatted call numbers were the most common problem reported by 76.9 percent of the respondents and physical processing errors were reported at the range of 0 to 3 percent. The most frequent physical errors included missing or incorrectly applied security tag, incorrectly formatted call numbers on spine labels, and incorrect placement of barcodes. Finally, it is not clear if or how shelf-ready operations influence a library's authority control practices because only Bierman and Carter briefly mention that authority work in their institution was not affected by shelf-ready services because it was done after cataloging. ${ }^{32}$

\section{Method}

\section{Research Questions and Conceptual Definitions}

The purpose of this research was to assess how US academic libraries manage shelf-ready materials and to provide the library community with recent data on how the implementation of shelf-ready models may affect technical services departments. The study was guided by the following questions:

1. Why did academic libraries implement shelf-ready services and did they manage shelf-ready materials differently?

2. What is the quality of bibliographic records for shelfready materials?

3. Do shelf-ready materials affect local procedures and cataloging practices?
4. What is the level of satisfaction with shelf-ready services and what do academic librarians think of their future expansion in academic libraries?

The authors designed the survey with the intent to gather this information from academic institutions with varying collection sizes. The questions in the survey were based on the research questions mentioned above.

The authors used the following conceptual definitions:

- The definition of "technical services department" was based on the description of technical services provided by the ODLIS: Online Dictionary of Library and Information Science: "library operations concerned with the acquisitions, organization (bibliographic control), physical processing, and maintenance of library collections." ${ }^{33}$ Conversely, for the purpose of this paper, "technical services department" was defined as a department where shelf-ready books were received or processed or both; it could be within acquisitions, cataloging, bindery/shelf preparation, or a combination of the above. Small libraries without technical services departments were referred to as "Library."

- "Shelf-ready materials" were defined as materials received from a vendor with full bibliographic records and some form of physical processing (e.g., barcodes, property stamps, spine labels, security devices, etc.).

\section{Sample and Study Population}

One of the main goals of the study was to investigate the differences in the management of shelf-ready materials by libraries of varying collection sizes. The selection of the study population presented a practical challenge because there was no readily available sample frame. There was not a single source of information listing all libraries with shelf-ready services from which the sample could be drawn. Therefore compiling the sample frame for the survey was a two-step process. First, the nonprobability purposive sample of four-year colleges was chosen from the Carnegie Foundation of Institutions of Higher Education (http://classifications.carnegiefoundation.org). The authors excluded two-year colleges from the study on the basis of data collected by Burke and Shorten. ${ }^{34}$ Their study specified that among institutions of varying sizes, 88 percent of two-year colleges were doing almost all cataloging in-house. Additionally, the authors wanted to concentrate on a group of libraries that was close in characteristics to their own institutions. Columbia University is a large research academic institution while B. Davis Schwartz Memorial Library at Long Island University Post Campus (LIU Post) is a medium-size academic library.

A stratified sample of thirty institutions was randomly 
chosen from all nine subgroups representing institutions of various sizes in the four-year colleges group. The authors used a random sample generator, Research Randomizer (www.randomizer.org), to select the sample. This strategy allowed the researchers to avoid self-selection of the survey respondents and to reach out to a diverse number of libraries of different collection sizes. The final sample frame consisted of a stratified random sample of 270 US academic libraries.

\section{Survey Instrument and Distribution}

Each library's website was accessed to collect email addresses for the individuals who were likely to be responsible for the management of shelf-ready materials. Each identified person received an email with an invitation to participate in the survey, an explanation of the research goal, and a link to an online survey form created via SurveyMonkey (www. surveymonkey.com), a web-based survey tool. The survey study population consisted of the heads of technical services departments, and technical services librarians including catalogers, acquisitions librarians, and other library practitioners directly involved in the management of shelf-ready materials. The email also asked recipients to forward the survey invitation to the appropriate personnel in their library if needed. A follow-up email with a reminder to participate in the survey was sent one week before the survey's closing date. The survey instrument comprised thirty-one questions (see appendix A) that addressed the demographic characteristics of the respondents and their libraries, the library's experience with shelf-ready materials management, quality of the bibliographic records, and evaluation of shelf-ready services. The survey questions were reviewed by three library administrators with cataloging or shelf-ready materials management experience from the authors' home institutions. The questions were multiple choice and in a closed-end format. Some of the multiple-choice questions provided an option for a free-text response. Several questions used skip logic that allowed the respondents to bypass questions depending on their answers. The participants did not have to answer all the questions, no incentives to complete the survey were offered, and no information that could identify the respondents was collected. The survey instrument was vetted through the LIU Post and Columbia University Institutional Review Boards and was exempt from review by both reviewing bodies.

\section{Data Analysis}

The survey was open from January 24-February 24, 2013. A total of forty-five replies were received. While the survey recruitment email aimed to convey the idea that the survey was geared toward libraries that had already implemented shelf-ready services, the data analysis revealed that among forty-five respondents, only twenty-seven libraries represented the targeted population (i.e., libraries that have implemented shelf-ready procedures) and fully completed the survey. The remaining eighteen respondents were from libraries that had only partially completed the survey and did not have shelf-ready procedures in place. They were eliminated from the poll of respondents. Not all respondents answered every question and the answers to some questions were not mutually exclusive. Consequently, the total number of responses may be less or greater than the total number of valid survey responses. The authors analyzed the free text replies submitted under the "other, please specify" option and collapsed the replies under existing categories when appropriate. The collected data were analyzed using the SPSS version 21 statistical software package. Although the use of stratified random sampling in this study carries great statistical validity by reducing sampling bias, the low response rate (10 percent) makes this study exploratory in nature. The resulting data should be discussed only regarding the type of library chosen.

\section{Survey Analysis and Discussion}

A total of twenty-seven valid responses were analyzed. The survey participants represented libraries of all sizes, with the majority working in either medium (ten or 37 percent) or small (eleven or 40.7 percent) size institutions. Large libraries were in the minority with six (22.2 percent) of respondents. Although the authors did not form a hypothesis regarding acceptance of shelf-ready services by a particular library size group, the latter finding may be indicative of the dissemination of shelf-ready services among institutions of different sizes. The survey reached its target audience with the majority of responses provided by either technical services librarians in management positions or other library administrators. The department heads made up the largest group (seventeen or 63.3 percent) of the respondents. In addition, two (7.4 percent) respondents had the job title "library director," and five (18.5 percent) were professional librarians or catalogers. The job titles of the remaining three survey participants included one bibliographic manager, one head of cataloging, and one cataloging unit head.

Regarding the number of the professional librarians, the majority (thirteen or 48 percent) of the responding institutions had four to seven professional librarians on staff. This group was composed of three large libraries, seven medium libraries and three small libraries. Only one large library had more than eleven professional librarians and a group of eight small libraries had fewer than three professionals working in technical services.

In relation to support staff, the majority of the respondents (ten of all libraries surveyed) reported employing 
Table 1. Reasons Cited for Shelf-Ready Implementation

\begin{tabular}{lrrrr}
\hline Motive & \multicolumn{2}{c}{ Library Size (No./\%) } \\
To reduce cost by downsizing technical services department & Large & Medium & Small & Total across all \\
To decrease workload of subject specialists & $3(50.0 \%)$ & $4(40.0 \%)$ & $1(9.1 \%)$ & $8(29.6 \%)$ \\
To improve material turnaround time & $1(16.7 \%)$ & $0(0.0 \%)$ & $1(9.2 \%)$ & $2(7.4 \%)$ \\
To redeploy staff for emerging priorities & $6(100.0 \%)$ & $8(80.0 \%)$ & $9(81.8 \%)$ & $23(85.2 \%)$ \\
\hline Other & $4(66.7 \%)$ & $8(80.0 \%)$ & $7(63.6 \%)$ & $19(70.4 \%)$ \\
\hline
\end{tabular}

between one to four paraprofessional staff. However, this group largely comprised the small libraries (nine or 81.8 percent). Large libraries predictably reported the biggest number of support staff with the majority (four or 66.7 percent) employing more than twenty support staff. The distribution of support staff in the medium-size libraries group varied widely. Half of the responding medium-size libraries (five or 50 percent) reported employing eleven to twenty support staff and the remaining half (five or 50 percent) reported employing five to ten support staff. Summary data on the survey demographics are presented in appendix B.

The first research question of the study related to the reasons for implementing shelf-ready services and the differences in the management of shelf-ready services at libraries of various sizes. The survey analysis revealed that the two main reasons for implementing shelf-ready services for libraries of all sizes were (1) the need to reduce materials turnaround time (twenty-three or 85.2 percent of all libraries) and (2) the desire to redeploy staff for other projects or emerging areas of need (nineteen or 70.4 percent of all libraries). Therefore shelf-ready services were viewed by libraries as an efficiency rather than a cost-cutting measure. Table 1 summarizes the reasons for the shelf-ready services implementation among libraries with varying collection sizes. Although the need to reduce cost by downsizing technical services departments was reported as a reason for shelf-ready implementation by almost one-third of the respondents (eight or 29.6 percent), the findings of this study support the focus on user satisfaction reported in previous research as the main driving force behind shelfready implementation. ${ }^{35}$ One small library specified that shelf-ready was implemented to ensure better preservation of library materials.

As to initial objections to shelf-ready implementation, survey respondents were divided roughly evenly between those who encountered objections (thirteen or 48.1 percent) and those who did not (fourteen or 51.9 percent). The two most common objections cited by all libraries were cost (seven or 25.9 percent of libraries) and quality of bibliographic records supplied (eight or 30 percent of libraries). Concern regarding the cost of shelf-ready services was somewhat surprising because, based on reasons for implementation described in the previous paragraph, cost should not have been one of the prevailing factors. However, the survey revealed that the predominant nature of objections varied along with the libraries' size. While medium (four or 40 percent) and small (two or 18.2 percent) academic libraries were mostly concerned with the cost and quality of vendor-supplied supplied bibliographic records, the main objection of the large libraries group (three or 50 percent) was on collection development control over shelf-ready materials. This was manifested in the subject specialists' desire to make book-by-book retention decisions. One might also argue that the subject specialists' time may be freed by employing shelf-ready services, thereby allowing them to pursue more challenging areas of collection development.

Only one library indicated the possible loss of staff positions as an objection to the shelf-ready implementation. In sum, the group of small libraries had the least number of objections compared to medium and large libraries. This could be explained by the fact that small libraries have fewer resources to invest in the in-house cataloging and processing of materials, making this group of libraries more open to the shelf-ready implementation. Table 2 summarizes data on initial objection to shelf-ready implementation.

The majority of responding institutions (eleven or 40.7 percent) had two to five years of experience using shelfready services. Libraries that had received shelf-ready materials for less than one year were in the minority (three or 11.1 percent). The survey data also indicated that the length of the individual libraries' experience with shelf-ready seemed dependent on library size. The majority of large libraries had received shelf-ready materials for more than ten years (three or 50 percent). In the medium libraries category, the majority had received shelf-ready for six to nine years (four or 40 percent). Most small libraries (six or 54.5 percent) received shelf-ready materials for two to five years. Large and medium libraries gradually integrated shelf-ready processes into their operations over the course of the last decade. In contrast, small libraries had more recent implementations of shelf-ready services.

Regarding budget, it was common for the majority of 
Table 2. Objections to Shelf-Ready Services Implementation

\begin{tabular}{|c|c|c|c|c|}
\hline \multirow[b]{2}{*}{ Nature of Objection } & \multicolumn{4}{|c|}{ Library Size (No./\%) } \\
\hline & Large & Medium & Small & Total across all \\
\hline Perception that shelf ready services result in delay in receiving materials & $0(0.0 \%)$ & $1(10.0 \%)$ & $0(0.0 \%)$ & $1(3.7 \%)$ \\
\hline Perception that materials supplied are out of scope or not scholarly & $1(16.7 \%)$ & $1(10.0 \%)$ & $0(0.0 \%)$ & $2(7.4 \%)$ \\
\hline Subject specialist wants to make book by book retention decisions & $3(50.0 \%)$ & $0(0.0 \%)$ & $0(0.0 \%)$ & $3(11.1 \%)$ \\
\hline Quality of cataloging records & $2(33.4 \%)$ & $4(40.0 \%)$ & $2(18.2 \%)$ & $8(30.0 \%)$ \\
\hline Loss of staff positions & $0(0.0 \%)$ & $0(0.0 \%)$ & $1(9.1 \%)$ & $1(3.7 \%)$ \\
\hline
\end{tabular}

Table 3. Changes in Cataloging Staff Level $(N=26)$

\begin{tabular}{|c|c|c|c|c|c|c|}
\hline \multirow[b]{2}{*}{ Libraries/Size } & \multicolumn{2}{|c|}{ Cataloging Staff Decreased } & \multicolumn{4}{|c|}{ Percentage of Decrease } \\
\hline & Yes & No & $50 \%+$ & $30 \%-50 \%$ & $10 \%-29 \%$ & Less than $10 \%$ \\
\hline Large & $1(20.0 \%)$ & $4(80.0 \%)$ & $0(0.0 \%)$ & $0(0.0 \%)$ & $1(16.7 \%)$ & $0(0.0 \%)$ \\
\hline Small & $3(27.3 \%)$ & $8(72.7 \%)$ & $1(9.1 \%)$ & $0(0.0 \%)$ & $2(18.2 \%)$ & $0(0.0 \%)$ \\
\hline Total across all library groups & $10(38.5 \%)$ & $16(61.5 \%)$ & $2(22.2 \%)$ & $1(11.1 \%)$ & $6(66.7 \%)$ & $0(0.0 \%)$ \\
\hline
\end{tabular}

libraries (fifteen or 68.2 percent) to use fewer than 5 percent of their acquisitions budget for shelf-ready services, with some medium and large libraries spending between 5 and 10 percent. It would be difficult to find an exact correlation between the percentage of the acquisitions budget used and the volume of shelf-ready materials received for large and medium institutions. The majority of large libraries (four or 66.7 percent) received 10,000-20,000 shelf-ready items annually. Among medium libraries, the two groups receiving $20,000+$ (three or 33.3 percent) and 5,000-10,000 (three or 33.3 percent) were most prevalent. An overwhelming majority (ten or 90.9 percent) of small libraries received fewer than 5,000 shelf-ready items annually. The surprising finding regarding shelf-ready budgets was that some medium-size libraries received the largest amount (more than 20,000 items) of shelf-ready materials while the percentage of the acquisitions budget for shelf-ready services in medium and large libraries was similar. This may be explained by a decrease in cataloging and processing resources in some medium libraries and the resulting acquisitions of larger amounts of shelf-ready materials. Consequently, medium libraries may be able to negotiate better prices with shelfready vendors on the basis of the amount of the materials received.

Overall, ten libraries (38.5 percent) reported a decrease in cataloging staff compared to sixteen libraries (61.5 percent) where cataloging staffing levels remained the same. Among those who reported a decrease, the majority (six or 66.7 percent) reported a $10-29$ percent decline in cataloging staff. Furthermore, shelf-ready services did not seem to significantly affect technical services staffing in large and small libraries. More than a half of medium libraries (six or 60 percent), however, reported a decrease in technical services personnel ranging from ten to fifty percent. Table 3 shows staff level changes as a result of shelf-ready implementation.

All twenty-seven libraries (100 percent) that responded to the survey reported that they receive shelf-ready print domestic monographs. Furthermore, seven (25.9 percent) received monographs from foreign vendors. Print monographs were also the largest category across all library sizes with only two libraries (7.4 percent) receiving shelf-ready serials. In contrast, nonprint materials (i.e., CDs and DVDs) were received by only one medium and one small library (7.4 percent of respondents). Although nonprint media are usually considered more difficult to catalog and process inhouse, the small number of libraries that chose to outsource this type of cataloging and physical processing may indicate the problems with bibliographic records quality as indicated in previous research. ${ }^{36}$ Across all library sizes, the categories excluded most commonly from shelf-ready services were rush materials (seventeen or 63 percent of all libraries) and added volumes (twelve or 44.4 percent of all libraries). The exclusion of the added volume category by most libraries may indicate problems with record loads and a need to monitor multivolume records and related processing more closely. To properly add an additional volume to an existing bibliographic record, libraries must develop procedures to correctly merge bibliographic records for initial and 
Table 4. Percentage of Materials Undergoing Quality Control $(N=20)$

\begin{tabular}{|c|c|c|c|c|}
\hline \multirow[b]{2}{*}{$\%$ of Materials } & \multicolumn{4}{|c|}{ Library Size (No./\%) } \\
\hline & Large & Medium & Small & Total across all \\
\hline All materials & $1(25.0 \%)$ & $2(25.0 \%)$ & $3(37.5 \%)$ & $6(30.0 \%)$ \\
\hline $5 \%-9 \%$ of materials & $1(25.0 \%)$ & $3(37.5 \%)$ & $0(0.0 \%)$ & $4(20.0 \%)$ \\
\hline Less than $5 \%$ of materials & $2(50.0 \%)$ & $1(12.5 \%)$ & $4(50.0 \%)$ & $7(35.0 \%)$ \\
\hline
\end{tabular}

consecutive volumes because each volume of shelf-ready multivolume work is typically received with its own bibliographic record.

The survey revealed that shelf-ready outsourcing constitutes a good example of a patron-oriented service model. Most libraries implemented shelf-ready services with the intent to enhance access to library resources to better serve users, and to free up staff to tackle new challenges. This form of outsourcing does not necessarily entail the reduction of technical services staff. Shelf-ready services involve mostly print monographs and serials and the type of materials excluded from this category is similar regardless of the library's size (see "Types of Shelf Ready Materials Received" table in appendix B). Likewise, libraries use similar financial approaches to budgeting for shelf-ready services. In sum, the collected data suggests that libraries of all sizes exercise a similar approach to their shelf-ready processing and the differences in management are insignificant. A summary of the shelf-ready services duration, cost, volume as well as type of materials received and excluded is included in appendix B.

The second research question pertained to the quality of bibliographic records received with shelf-ready services. Quality control applied to received materials was important for an overwhelming majority (95.8 percent) of libraries. Virtually all institutions performed some form of bibliographic and physical processing review. Large and medium libraries mostly relied on support staff (66 and 90 percent respectively) to perform quality control with some input from professional librarians, whereas small libraries equally involved both professionals and support staff (45.5 and 54.5 percent respectively). Thus the survey results suggest that shelf-ready processing is a good redeployment of support staff within the technical services departments of academic libraries.

The majority of responding libraries (fifteen or 68.2 percent) performed quality control of shelf-ready materials as an ongoing activity. This was true across all library categories with 100 percent of large, 66.7 percent of medium, and 55.6 percent of small libraries adhering to this practice. It is interesting to note that while large and medium libraries mostly performed quality control as an ongoing activity, small libraries demonstrated a wide range of practices (from the first year only to an ongoing activity). Perhaps this may be explained by the fact that small libraries implemented shelf-ready services relatively recently compared to the rest of the group and continue to investigate different models of quality control procedures. Table 4 reveals data on individual libraries' approaches to the percentage of shelf-ready material that is subject to quality control. There was no consistency between survey respondents regarding the percentage of the materials examined: the numbers varied between inspecting 100 percent of shelf-ready materials received to fewer than 5 percent.

Table 5 reports on physical processing errors encountered by the survey participants. The majority of physical processing errors were related to spine label mistakes (twelve or 44.4 percent of all libraries) followed by errors related to barcode placement, security tag, or property stamp errors (nine or 33.3 percent of all libraries). Two libraries (7.4 percent) reported an absence of physical processing mistakes. Table 6 reports on cataloging errors. The major cataloging error noted by libraries of all sizes was the absence of a call number in the bibliographic record (seventeen or 63 percent of all libraries). Access point errors constituted the smallest group, as reported by 14.8 percent of all libraries, and were noticed only by medium-size libraries. The percentage of other types of cataloging errors was significantly smaller, and the types of errors were fairly equally distributed across libraries of various collection sizes.

The reported error rate for combined cataloging and physical processing mistakes was insignificant. The majority of libraries (fifteen or 55.6 percent) estimated a $0-3$ percent cataloging and physical processing error rate in their shelf-ready workflow. This was true for libraries of all sizes. Table 7 reports error rate and areas of concern. Although the percentages of examined materials varied, libraries of all sizes were predominantly concerned with bibliographic errors and mistakes in record loads (twelve or 57.2 percent of all libraries). Shipments, invoices, and profiles generated the least amount of errors (two or 9.5 percent of libraries). Another category (two or 9.5 percent of libraries) included "defects in books not being caught by a vendor" and "OCLC unable to supply record." As previously mentioned, most libraries reported less than 3 percent error rate, and this 
Table 5. Physical Processing Errors $(N=22)$

\begin{tabular}{lcccc}
\hline & & \multicolumn{2}{c}{ Library Size (No./\%) } \\
Error Type & Large & Medium & Small & Total across all \\
Spine label mistakes (call number, location, volume number) & $3(50.0 \%)$ & $6(60.0 \%)$ & $3(27.3 \%)$ & $12(44.4 \%)$ \\
Barcode, security tag or stamp errors (missing, incorrectly applied) & $3(50.0 \%)$ & $4(40.0 \%)$ & $2(18.2 \%)$ & $9(33.3 \%)$ \\
None & $1(10.0 \%)$ & $0(0.0 \%)$ & $1(10.0 \%)$ & $2(7.4 \%)$ \\
\hline
\end{tabular}

Table 6. Cataloging Errors $(N=22)$

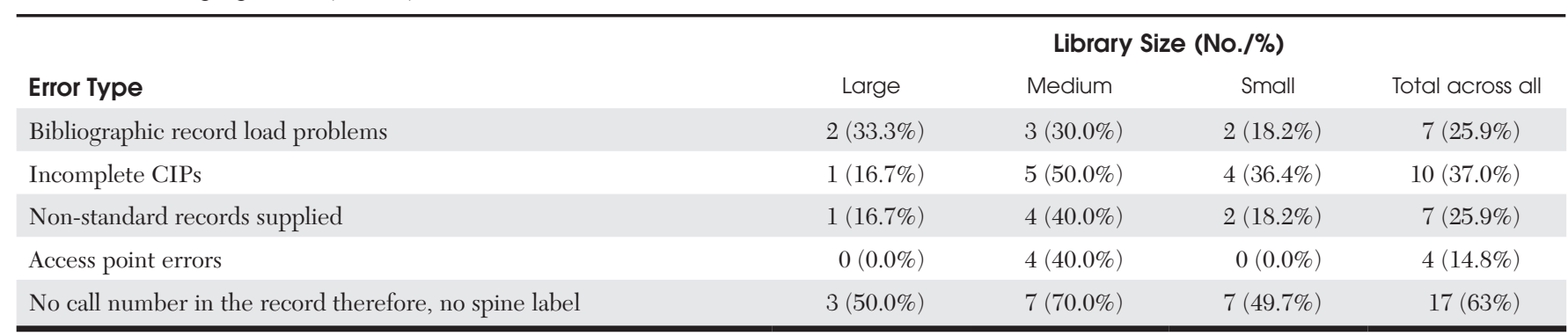

number is consistent with the error rate recorded by Sanchez in her 2011 shelf-ready study. ${ }^{37}$ The survey data also confirms previous findings reported in Lam's and Schroeder and Howland's case studies regarding a very low rate of bibliographic record errors in shelf-ready materials. ${ }^{38}$ Although the quality of bibliographic records presented a major objection to implementing shelf-ready services in libraries of all sizes, the findings of this study prove that once shelf-ready services were implemented, record quality concerns were alleviated. Detailed data on staff involvement, years of experience, percentage of materials undergoing quality control as part of the shelf-ready services are provided in appendix B.

The third research question addressed the effect of shelf-ready services on local procedures and cataloging practices. More than half the libraries (fourteen or 60.9 percent) reported that their in-house cataloging practices were affected by shelf-ready services. Among the libraries of various collection sizes, the medium-size libraries group (eight or 88.9 percent) was the most likely to modify or abandon some of their cataloging workflows. Perhaps these findings are related to the fact that medium libraries proved to be the largest consumer of shelf-ready records and therefore statistically experienced the greatest effect on their local workflows. The number of respondents who indicated that cataloging practices were affected was relatively close to the number of libraries which did not experience any changes in cataloging practices (nine or 39.1 percent). This may be explained by the fact that libraries take a different approach when it comes to database maintenance practices and have different amounts of available shelf space. As a result, some institutions are ready to allow for greater deviations in shelf listing and are more willing to accept records that do not conform precisely to their local practices. Yet others prefer to exercise stricter control and therefore need to modify local practices to accommodate shelf-ready materials. The majority of libraries modified, rather than abandoned, their local cataloging practices because of shelf-ready services.

The survey results demonstrated that shelf-ready services did not affect the way authority control was performed in the majority (95.5 percent) of libraries. The authors assumed that most libraries perform authority control inhouse or use authority control vendors post-cataloging. All twenty-three libraries that answered the question about the possible effect of RDA on technical specifications for shelf-ready services responded that the increased number of RDA records would not affect shelf-ready specifications. Perhaps it is safe to speculate that many libraries have already adjusted bibliographic load tables in their integrated library systems in anticipation of RDA implementation. As the adoption of RDA expands, libraries receiving shelf-ready bibliographic records might need to work with vendors on technical specifications related to the specific RDA elements such as content, media, and carrier.

The intent of the fourth research question was to assess the level of satisfaction with shelf-ready services and the future of this outsourcing model in academic libraries. The survey data confirmed that most categories of libraries were satisfied with the shelf-ready services they receive. Half (eleven or 50 percent) of respondents chose "very satisfied" as the answer, and a little less than one-third (six or 27.3 percent) indicated that they were satisfied with the services. Libraries that were moderately or not satisfied were in the minority (11.1 and 9.1 percent, respectively). The majority of libraries from the latter category were either small or 
Table 7. Error Rate and Areas of Concern $(N=22)$

\begin{tabular}{|c|c|c|c|c|}
\hline \multirow[b]{2}{*}{ Error Rate } & \multicolumn{4}{|c|}{ Library Size (No./\%) } \\
\hline & Large & Medium & Small & Total across all \\
\hline $0-3 \%$ & $4(66.7 \%)$ & $5(50.0 \%)$ & $6(54.5 \%)$ & $15(55.6 \%)$ \\
\hline $7-10 \%$ & $0(0.0 \%)$ & $1(10.0 \%)$ & $2(18.2 \%)$ & $3(11.1 \%)$ \\
\hline $11-15 \%$ & $0(0.0 \%)$ & $0(0.0 \%)$ & $1(9.1 \%)$ & $1(3.7 \%)$ \\
\hline \multicolumn{5}{|l|}{ Area of Concern: } \\
\hline Bibliographic records and loads & $1(25.0 \%)$ & $5(55.6 \%)$ & $6(75.0 \%)$ & $12(57.2 \%)$ \\
\hline Physical processing (barcoding, labeling, etc.) & $2(50.0 \%)$ & $3(33.3 \%)$ & $2(25.0 \%)$ & $7(33.3 \%)$ \\
\hline Shipment, invoices, profiles & $1(25.0 \%)$ & $1(11.1 \%)$ & $0(0.0 \%)$ & $2(9.5 \%)$ \\
\hline \multicolumn{5}{|l|}{ Other: } \\
\hline
\end{tabular}

medium institutions. The medium group could have experienced the most problems with shelf-ready implementation because they were the largest group participating in the survey.

The positive feedback on the quality of the shelf-ready services was received mostly from technical services personnel (seventeen or 63 percent of respondents). Public services librarians provided feedback from nine (33.3 percent) of the surveyed institutions, and user feedback was cited by seven (25.9 percent) libraries. Predictably, the majority of the feedback was provided by technical services staff. Perhaps, with the support of library administration, the assessment of the shelf-ready services efficiencies may further involve public services staff and patrons. Although the majority of libraries expressed satisfaction with shelf-ready services, the survey participants were less positive regarding the possible expansion of this service at their institutions. A little less than half of the libraries strongly agreed (six or 27.3 percent) or agreed (four or 18.2 percent) with the statement that future expansion of shelf-ready services in their institutions would possibly include new vendors and new categories of materials. However, more libraries disagreed (four or 18.2 percent), strongly disagreed (one or 4.5 percent), or had no definitive response (seven or 31.8 percent) to this statement. Therefore the survey failed to predict the future expansion of shelf-ready services in academic libraries. Perhaps further development of shelf-ready services by vendors might change this uncertain outlook.

\section{Conclusion}

The survey provided an overview of the implementation, management, and evaluation of shelf-ready services in academic libraries. The main reasons for shelf-ready implementation across libraries of all sizes were the need to improve materials turnaround time and the desire to redeploy staff for other projects or tasks. An additional efficiency is gained by the fact that shelf-ready materials bibliographic records have a very low error rate. The survey results also demonstrated that the academic library community is focused not only on the timely processing of print materials but also on the quality of the shelf-ready physical processing. Bibliographic control remains a valid concern. The survey results confirmed that shelf-ready services have not been affected by the implementation of RDA and authority work now. The results of the survey may assist library administrators in making informed decisions regarding the implementation of shelf-ready services at their institutions and the possible implications of these services for database quality and staff management. The survey data may also encourage libraries to reevaluate existing procedures and inspire new approaches to processing of print materials in US academic libraries. The authors plan to focus their future research on more specialized aspects of shelf-ready services such as foreign vendors' capabilities to provide shelf-ready services according to US libraries'specifications.

\section{References}

1. Albert H. Joy and Rick Lugg, "The Books Are Shelf-Ready; Are You?," Library Acquisitions 22, no. 1 (1998): 71-89; Mary Walker and Deb Kulczak, "Shelf-ready Books Using PromptCat and YBP: Issues to Consider (An Analysis of Errors at the University of Arkansas)," Library Collections, Acquisitions, \& Technical Services 31, no. 2 (2007): 61-84; Vinh-The Lam, 
"Quality Control Issues in Outsourcing Cataloging in United States and Canadian Academic Libraries," Cataloging \& Classification Quarterly 40, no. 1 (2005): 101-22.

2. James H. Sweetland, "Outsourcing Library Technical Services-What We Think We Know, and Don't Know,” Bottom Line: Managing Library Finances 14, no. 3 (2001): 169.

3. Sarah Shippy and Emily Krug, "Transforming Technical Services: Are You Ready to Go 'Shelf-Ready"?" Tennessee Libraries 62, no. 2 (2012), accessed December 2, 2012, http://tnla. org/displaycommon.cfm?an=1\&subarticlenbr $=484$.

4. Joy and Lugg, "The Books Are Shelf-Ready; Are You?" 73.

5. Ibid.,76.

6. Vihn-The Lam, "Quality Control Issues in Outsourcing Cataloging," 105; John Ballestro, "Losing Your Control: Acquisitions and Outsourcing," Technical Services Quarterly 29, no. 2 (2012): 120; Shippy and Krug, "Transforming Technical Services"; Kenneth J. Bierman and Judith A. Carter, "Outsourcing Monograph Cataloging at the UNLV Libraries," Technical Services Quarterly 25, no. 3 (2008): 50.

7. Shippy and Krug, "Transforming Technical Services."

8. Sweetland, "Outsourcing Library Technical Services," 170-72.

9. Vihn-The Lam, "Quality Control Issues in Outsourcing Cataloging," 106.

10. Bierman and Carter, "Outsourcing Monograph Cataloging," 64.

11. José Luis Andrade et al., “'Shelf-Ready’ Print Serials Acquisitions," Serials Review 37, no. 1 (2011): 29-34.

12. David Baron, "Shelf Ready Processing at Leeds Metropolitan University," Catalogue \& Index no. 166 (2012): 2-4.

13. Beth E. Jacoby, "Status of Approval Plans in College Libraries," College \& Research Libraries 69, no. 3 (2008): 227-40.

14. Joy and Lugg, "The Books Are Shelf-Ready," 78-79.

15. Bierman and Carter, "Outsourcing Monograph Cataloging," 51.

16. Sweetland, "Outsourcing Library Technical Services," 170; Bierman and Carter, "Outsourcing Monograph Cataloging," 62; David Baron, "Shelf Ready Processing at Leeds Metropolitan University," Catalogue \& Index, no. 166 (2012): 4.

17. Rebecca Schroeder and Jared L. Howland, "Shelf-Ready: A Cost-Benefit Analysis," Library Collections, Acquisitions \& Technical Services 35, no. 4 (2011): 129-34.

18. Bierman and Carter, "Outsourcing Monograph Cataloging,"
61.

19. Ibid., 56 .

20. Walker and Kulczak, "Shelf-ready Books," 63.

21. Bierman and Carter, "Outsourcing Monograph Cataloging," 63.

22. Sweetland, "Outsourcing Library Technical Services," 170172.

23. Walker and Kulczak, "Shelf-Ready Books," 80-81; Vinh-The Lam, "Error Rates in Monograph Copy Cataloging Bibliographic Records Before and After Outsourcing at the University of Saskatchewan Library," Cataloging \& Classification Quarterly 44, no. 3/4 (2007): 213-20.

24. Baron, "Shelf Ready Processing," 4.

25. Vinh-The Lam, "Quality Control Issues in Outsourcing Cataloging," 109-11.

26. Walker and Kulczak, "Shelf-Ready Books," 62.

27. Vinh-The Lam, "Error Rates in Monograph Copy Cataloging," 220.

28. Schroeder and Howland, "Shelf-Ready," 133.

29. Michael Jay, Betsy Simpson, and Doug Smith, "CatQC and Shelf-Ready Material: Speeding Collections to Users While Preserving Data Quality," Information Technology \& Libraries 28, no. 1 (2009): 41-48.

30. Ballestro, "Losing Your Control," 116-17.

31. Elaine Sanchez, email to Autocat discussion list, November 16, 2011.

32. Bierman and Carter, "Outsourcing Monograph Cataloging," 60.

33. ODLIS: Online Dictionary of Library and Information Science, s.v. “technical services," accessed November 11, 2013, www.library.ucsb.edu/research/db/1182.

34. Susan K. Burke and Jay Shorten, "Name Authority Work Today: A Comparison of Types of Academic Libraries," Library Resources \& Technical Services 54, no. 1(2010): 4-20.

35. Vihn-The Lam, "Quality Control Issues in Outsourcing Cataloging," 105; Ballestro, "Losing Your Control," 120; Bierman and Carter, "Outsourcing Monograph Cataloging," 50.

36. Baron, "Shelf Ready Processing," 4.

37. Sanchez, email to Autocat discussion list.

38. Vihn-The Lam, "Quality Control Issues in Outsourcing Cataloging," 114; Schroeder and Howland, "Shelf-Ready," 133. 


\section{Appendix A. Ready or Not? An Assessment of Shelf-Ready Materials Management Practices in US Academic Libraries}

\section{Survey Questions}

Survey terminology: Technical Services department is a department where shelf ready books are received and (or) processed; it could be the Acquisitions, Cataloging, or Bindery/Shelf Preparation department or a combination of the above. Small libraries without Technical Services Departments are referred to as "Library." Shelf ready materials are defined as materials received from a vendor with cataloged records and with at least some physical processing (e.g., barcodes, property stamps, spine labels, security devices, etc.).

1. To which category does your Library belong? - Large (more than 6 million volumes in Library)

- Medium (2-6 million volumes in Library)

- Small (less than 2 million volumes in Library)

2. What is your position within Technical Services Department/Library?

- Director

- Head of department

- Professional librarian/Cataloger

$\circ$ Other (Please specify)

3. How many professional librarians does your Technical Services Department/Library have?

- More than 11

o $8-10$

○ $4-7$

- Less than 3

4. How many library assistants/library technicians does your Technical Services Department/Library have?

o More than 20

- 11-20

○ $5-10$

○ $4-1$

○ None

5. Why did your Library implement shelf ready services? (select all that apply)

○ To reduce cost by downsizing Technical Services Department

- To decrease workload of subject specialists

- To improve materials turnaround time

○ To redeploy staff for emerging priorities

- Other (Please specify)

6. Were there any initial objections into the implementation of shelf ready services in your Library? (contingency question, participants that replied "yes" are directed to Q.7., otherwise skip to Q8)

$\circ$ No

$\circ$ Yes
7. Please indicate the nature of initial objections (select all that apply)

- Perception that shelf-ready services result a delay in receiving materials

o Shelf-ready services were perceived as more expensive than in-house processing and labeling

o There was a concern that shelf-ready services negatively affect ILL lending and patron requests

- Perception that material supplied is out of scope or not scholarly

- Subject specialists want to make book by book retention and shelving decisions

- Other (please specify)

8. For how many years has your Library been receiving shelf ready materials?

$\circ$ More than 10 years

$\circ$ 6-9 years

○ $2-5$ years

o Less than 1 year

9. What type of materials does your Library receive shelf ready? (select all that apply)

- Print (domestic vendors)

○ Print (foreign vendors)

o Serials

○ DVDs

$\circ$ CDs

- Other (Please specify)

10. What kind of materials are excluded from shelf ready services in your library? (select all that apply)

○ Added volumes

- Oversize

- Rush materials

- Certain library locations (e.g. reference)

- Other (please specify)

11. What is the volume of the shelf ready supplied materials?

- More than 20,000 items/year

○ 10,000-20,000 items/year

$\circ 5,000-10,000$ items/year

○ Less than 5,000 items/year

12. Has your cataloguing staffing level decreased as a result of shelf ready? (contingency question, participants answering "yes" are redirected to Q13, otherwise skip to Q14)

$\circ$ Yes

$\circ$ No 
13. What is the percentage of decrease?

- More than $50 \%$

○ $30 \%-50 \%$

- $10 \%-29 \%$

- Less than $10 \%$

14. What is your cost for shelf ready services?

- More than $20 \%$ of acquisitions budget

- 11\%-20\% of acquisitions budget

- $5 \%-10 \%$ of acquisitions budget

- Less than $5 \%$ of acquisitions budget

15. Has your institution ever performed quality control of shelf ready materials? (participants answering "no" are redirected to Q23)

$\circ$ Yes

$\circ$ No

16. How long did you perform quality control of shelf ready materials?

○ First 6 months

$\circ$ First year

- First two years

- As an ongoing activity within the Technical Services Department

17. What level of staff are involved in the quality control program? (select all that apply)

- Librarians

- Library assistants/technicians

18. On what percentage of materials do you perform quality control?

○ All materials

- $10 \%$ of materials

○ 5\%-9\% of materials

- Less than $5 \%$ of materials

- Other (Please specify)

19. What kinds of physical processing errors have you encountered? (select all that apply)

- Spine label mistakes (call number, location, volume number(s))

- Barcode, security tag or stamp errors (missing, incorrectly applied)

- Other (please specify)

20. What kinds of cataloging errors have you encountered? (select all that apply)

- Bibliographic record load problems

- Incomplete CIPs

- Non-standard records supplied

- Access point errors

- No call number in the record (therefore, no spine label either)

○ Other (please specify)
21. To date, what has been the overall rate of all errors (bibliographic and physical processing)?

$\circ 0-3$ percent

○ 4-6 percent

○ $7-10$ percent

- $11-15 \%$

- More than $15 \%$

22. The majority of errors are related to:

- Bibliographic records and loads

- Physical processing (barcoding, labeling, etc.)

- Shipment, invoices, and profiles

o Other

23. Have your local cataloging practices been affected by shelf ready? (contingency question, participants answering "yes" are directed to Q24, otherwise skip to Q25 )

$\circ$ No

$\circ$ Yes

24. How the local cataloging / processing practices were affected?

- Library had to modify certain in-house practices to accommodate shelf ready

- Library had to abandon certain in-house practices to accommodate shelf ready

o Other

25. Have the shelf ready services affected authority control processes in your Library? (contingency question, participants answering "yes" are redirected to Q26, otherwise skip to Q27)

$\circ$ No

$\circ$ Yes

26. Please briefly describe how the authority control processing was affected

27. Does the increased number of RDA records affect (or will affect) the technical specifications for your shelf ready vendor? (contingency question, participants answering "yes" are directed to Q28, otherwise skip to Q29)

$\circ$ No

$\circ$ Yes

28. Please briefly describe the changes in specifications.

29. Please rate the level of satisfaction with shelf ready services:

○ Very satisfied

o Satisfied

- Moderately satisfied

○ Not satisfied 
30. Is your perception of the success or failure of the shelf ready services based on feedback from the following groups (select all that apply)
○ Users
- Public Services staff
- Technical Services staff
$\circ$ Others (please specify)

31. Please rank the following statement: "My Library is planning to expand shelf ready services in the future (possibly including new vendors and new categories of materials)"
○ Agree
$\circ$ Strongly agree
- Disagree
○ Strongly disagree
○ Don't know

\section{Appendix B}

\section{Distribution of Professional Staff in Respondents Institutions}

\section{Type of Library}

Large (more than 6 million volumes in Library)

Medium (2-6 million volumes in Library)

Small (less than 2 million volumes in Library)

Total \% across all groups

II. Distribution of Paraprofessional Staff in Respondents Institutions

Type of Library

Large (more than 6 million volumes)

Medium (2-6 million volumes)

Small (less than 2 million volumes

Total \% across all groups

III. Years Receiving Shelf-Ready Materials

\begin{tabular}{|c|c|c|c|c|}
\hline \multirow[b]{2}{*}{ Library Size } & \multicolumn{4}{|c|}{ Range of Years Receiving Shelf Ready Services } \\
\hline & $10+$ & $6-9$ & $2-5$ & $<1$ year \\
\hline Large & $3(50 \%)$ & $1(16.7 \%)$ & $2(33.3 \%)$ & $0(0.0 \%)$ \\
\hline Small & $0(0.0 \%)$ & $2(18.2 \%)$ & $6(54.5 \%)$ & $3(27.3 \%)$ \\
\hline Total across all groups & $6(22.2 \%)$ & $7(25.9 \%)$ & $11(40.7 \%)$ & $3(11.1 \%)$ \\
\hline & \multicolumn{4}{|c|}{ Library Size (No. / \%) } \\
\hline Acquisitions Budget & Large & Medium & Small & Total for all \\
\hline $20 \%+$ & $0(0.0 \%)$ & $1(14.3 \%)$ & $1(10 \%)$ & $2(9.1 \%)$ \\
\hline $11 \%-20 \%$ & $0(0.0 \%)$ & $0(0.0 \%)$ & $0(0.0 \%)$ & $0(0.0 \%)$ \\
\hline
\end{tabular}

Professional Staff Range (No. / \%)

\begin{tabular}{crrr}
$11+$ & $8-10$ & $4-7$ & \multicolumn{1}{c}{$<3$} \\
$1(16.7 \%)$ & $1(16.7 \%)$ & $3(50 \%)$ & $1(16.7 \%)$ \\
$0(0.0 \%)$ & $1(10 \%)$ & $7(70 \%)$ & $2(20 \%)$ \\
$0(0.0 \%)$ & $0(0.0 \%)$ & $3(27.3 \%)$ & $8(72.7 \%)$ \\
$1(3.7 \%)$ & $2(7.4 \%)$ & $13(48.1 \%)$ & $11(40.7 \%)$
\end{tabular}

Professional Staff Range (No. / \%)

\begin{tabular}{rrrr}
$20+$ & $11-20$ & \multicolumn{1}{c}{$5-10$} & \multicolumn{1}{c}{$4-1$} \\
$4(66.7 \%)$ & $1(16.7 \%)$ & 0 & $1(16.7 \%)$ \\
$0(0.0 \%)$ & $5(50 \%)$ & $5(50 \%)$ & $0(0.0 \%)$ \\
$0(0.0 \%)$ & $1(9.1 \%)$ & $1(9.1 \%)$ & $9(81.8 \%)$ \\
4 & 7 & 6 & 10
\end{tabular}




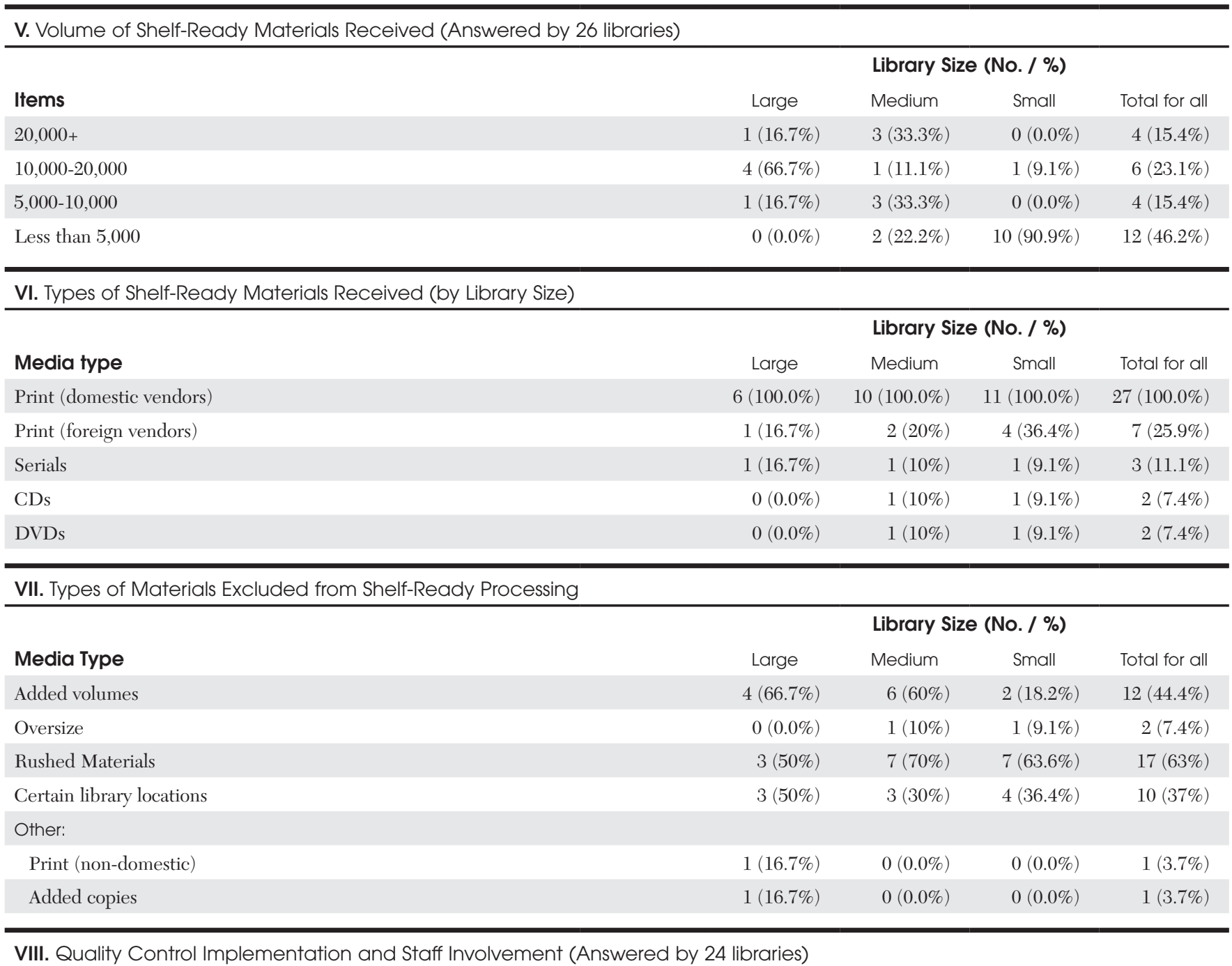

VIII. Quality Control Implementation and Staff Involvement (Answered by 24 libraries)

Quality Control Performed

\begin{tabular}{|c|c|c|c|c|}
\hline \multirow[b]{2}{*}{ Libraries/Size } & \multicolumn{2}{|c|}{ Performed } & \multicolumn{2}{|c|}{ Staff Involved } \\
\hline & Yes & No & Librarians & $\begin{array}{l}\text { Library } \\
\text { Assistants/ } \\
\text { Tech }\end{array}$ \\
\hline Large & $5(100.0 \%)$ & $0(0.0 \%)$ & $2(33.3 \%)$ & $4(66.7 \%)$ \\
\hline Medium & $8(100.0 \%)$ & $0(0.0 \%)$ & $3(30.0 \%)$ & $9(90.0 \%)$ \\
\hline Small & $10(90.9 \%)$ & $1(9.1 \%)$ & $5(45.5 \%)$ & $6(54.5 \%)$ \\
\hline Total across all library groups & $23(95.8 \%)$ & $1(4.2 \%)$ & $10(37.0 \%)$ & $19(70.4 \%)$ \\
\hline \multicolumn{5}{|c|}{ IX. Years of Performing Quality Control of Shelf-Ready Materials (Answered by 22 Libraries) } \\
\hline & \multicolumn{4}{|c|}{ Library Size (No. / \%) } \\
\hline Time Frame & Large & Medium & Small & Total for all \\
\hline First 6 months & $0(0.0 \%)$ & $2(22.2 \%)$ & $0(0.0 \%)$ & $2(9.1 \%)$ \\
\hline First year & $0(0.0 \%)$ & $1(11.1 \%)$ & $4(44.4 \%)$ & $5(22.7 \%)$ \\
\hline First two years & $0(0.0 \%)$ & $0(0.0 \%)$ & $0(0.0 \%)$ & $0(0.0 \%)$ \\
\hline As an on-going activity & $4(100 \%)$ & $6(66.7 \%)$ & $5(55.6)$ & $15(68.2 \%)$ \\
\hline
\end{tabular}




\begin{tabular}{|c|c|c|c|c|c|}
\hline Libraries/Size & \multicolumn{2}{|c|}{$\begin{array}{c}\text { Cataloging Practices } \\
\text { Affected }\end{array}$} & \multicolumn{3}{|c|}{ Level } \\
\hline Large & $2(50 \%)$ & $2(50 \%)$ & $2(100 \%)$ & $0(0.0 \%)$ & $0(0.0 \%)$ \\
\hline Medium & $8(88.9 \%)$ & $1(11.1 \%)$ & $7(87.5 \%)$ & $1(12.5 \%)$ & $2(20 \%)$ \\
\hline \multicolumn{6}{|c|}{ XI. Level of Satisfaction with Shelf-Ready Services (Answered by 22 libraries) } \\
\hline & & \multicolumn{4}{|c|}{ Library Size (No. / \%) } \\
\hline Level & & Large & Medium & Small & Total for all \\
\hline Not Satisfied & & $0(0.0 \%)$ & $1(11.1 \%)$ & $1(11.1 \%)$ & $2(9.1 \%)$ \\
\hline \multicolumn{6}{|c|}{ XII. Source of Feedback on Shelf-Ready Services } \\
\hline & & \multicolumn{4}{|c|}{ Library Size (No. / \%) } \\
\hline & & Large & Medium & Small & Total for all \\
\hline Public services & & 2 & 5 & 2 & $9(33.3 \%)$ \\
\hline Technical services & & 3 & 7 & 7 & $17(63 \%)$ \\
\hline Users & & 1 & 2 & 4 & $7(25.9 \%)$ \\
\hline Other & & 0 & 2 & 1 & $3(13.5 \%)$ \\
\hline Disagree & & 1 & 3 & 0 & $4(18.2 \%)$ \\
\hline Strongly disagree & & 0 & 0 & 1 & $1(4.5 \%)$ \\
\hline Don't know & & 0 & 2 & 5 & $7(31.8 \%)$ \\
\hline
\end{tabular}

